Ensino, Saúde e Ambiente - v. 14 n. esp. (2021): Dossiê Paulo Freire para além dos 100 anos:

construir utopias, transformar a realidade, p. 512-535.

Questão Ambiental e Promoção da Saúde

\title{
Diálogos entre Paulo Freire e Vandana Shiva como aportes para uma Educação Ambiental desde el Sur
}

\section{Dialogues between Paulo Freire and Vandana Shiva as contributions to an Environmental Education from the South}

\section{Carolina Alves Gomes de Oliveira ${ }^{1}$}

1 Doutora em Educação (UNIRIO), Universidade Federal do Estado do Rio de Janeiro, Rio de Janeiro, RJ, Brasil - E-mail: agoliva86@gmail.com / ORCID https://orcid.org/0000-0001-9854-8581

Palavras-chave: Paulo Freire; Vandana Shiva; educação ambiental

\section{Keywords:}

Paulo Freire; Vandana Shiva; environmental education
RESUMO: Este trabalho propõe o diálogo entre o educador Paulo Freire e a cientista e ambientalista Vandana Shiva como terreno fértil para se pensar conceitos, valores e práticas alinhados à perspectiva de uma Educação Ambiental desde el Sur. Considerando a importância destes dois pensadores para se pensar a educação em sua dimensão libertadora e o ecologismo popular, respectivamente, buscamos, em suas principais obras, pontos de encontro e discussão capazes de provocar reflexões sobre o papel da Educação Ambiental na transformação das relações socioambientais. Como principais pontos de diálogo levantamos: a identificação das opressões, a importância da cultura popular e dos saberes ancestrais, a sociobiodiversidade como base para os inéditos- viáveis e a Educação Ambiental desde el Sur como promotora da humanização, desalienação e interdependência. Estes elementos nos atentam para a necessidade do aumento da criticidade e do comprometimento da Educação Ambiental com a perspectiva dos grupos subalternizados, cujas resistências vêm produzindo alternativas que se nutrem da sociobiodiversidade.

ABSTRACT: This work proposes the dialogue between the educator Paulo Freire and the scientist and environmentalist Vandana Shiva as a fertile ground for thinking about concepts, values and practices aligned with the perspectiva of an Environmental Education from the South. Considering the importance of these two thinkers to think about education in it's liberating dimention and popular ecologism, respectively, we search, in their main works, meeting and discussion points capable of provoking reflections about the role of Environmental Education in the transformation of socioenvironmental relations. As main dialogue's points we raise: the identification of oppressions, the importance of popular culture and ancestral knowledge, sociobiodiversity as the basis for the unpressedent- viable, and Environmental Education from the South as a promoter of humanization, de-alienation and interdependence. These elements make us awere of the need to encrease the criticality and commitment of Environmental Education with the perspective of subalternized groups, whose resistence has been producing alternatives that feed on socio-biodiversity. 
Ensino, Saúde e Ambiente - v. 14 n. esp. (2021): Dossiê Paulo Freire para além dos 100 anos: construir utopias, transformar a realidade, p. 512-535.

Questão Ambiental e Promoção da Saúde

\section{INTRODUÇÃO}

Diante do atual desmantelamento das redes políticas e instituições que dão corpo à Educação Ambiental brasileira, somos impelidos a refletir sobre as causas do crescente antiambientalismo que se aloja em nossa sociedade, através de discursos políticos e ideológicos autoritários (LAYRARGUES, 2020). O ataque aberto ao "ambiental”, como tudo aquilo que se opõe ao crescimento econômico, à geração de empregos, à exploração dos recursos naturais e ao desenvolvimento, parece endossar os argumentos daqueles que permanecem se beneficiando com a dicotomia "ser humano versus natureza". Isso nos faz refletir sobre o papel que a Educação Ambiental, dentro de suas diferentes vertentes, vem desempenhando na reafirmação ou na problematização desse paradigma.

Em contrapartida, não se pode negar o avanço dos esforços no sentido da politização das discussões ambientais nos centros acadêmicos e até mesmo nas escolas e ambientes não formais de ensino. No entanto, a força do discurso hegemônico se faz presente e constante nas propagandas, nos programas empresariais que se instalam nas escolas, nas determinações dos órgãos internacionais para as políticas públicas; de forma que a Educação Ambiental permanece assumindo, grade parte das vezes, o papel de propagadora de comportamentos individuais e conciliadora entre os interesses econômicos corporativos e a sustentabilidade (LAYRARGUES; LIMA, 2014).

É no sentido de retomar a dimensão subversiva e contestatória da Educação Ambiental, a partir da perspectiva do Sul global, que a Educação Ambiental de base Comunitária (EABC) em diálogo com a Educação Ambiental Crítica e com a Ecologia Política latino-americana, vem propondo junto aos grupos populares, outras possibilidades de encontro (SARRIA et. al., 2018). A reconexão entre as dinâmicas sociais, políticas e ambientais, se fazem claras, sobretudo na experiência dos grupos populares organizados, cujos ensinamentos provêm da prática e o conhecimento não se restringe aos "cérebros dos especialistas", mas reverbera nos corpos e nos territórios.

É nesse sentido que no presente ensaio trazemos duas importantes referências para se pensar um ambientalismo humanizado, uma educação ambiental localizada, pluricultural e gestada junto aos grupos populares. Lançamos o desafio de trançar diálogos possíveis entre Paulo Freire e Vandana Shiva, compreendendo nos encontros entre pensamentos, práticas, tempos e espaços campos de possibilidades para encarar uma das mais difíceis "situações- 
Ensino, Saúde e Ambiente - v. 14 n. esp. (2021): Dossiê Paulo Freire para além dos 100 anos: construir utopias, transformar a realidade, p. 512-535.

\section{Questão Ambiental e Promoção da Saúde}

limites" de nosso tempo - a crise civilizatória capitalista. Nossa motivação se orienta pelas importantes contribuições que o educador e pensador brasileiro e a ambientalista e teórica indiana vêm trazendo para se pensar uma educação ambiental que integre a preservação da natureza à luta contra as injustiças e a desumanização, no Sul global. Com isso, a partir da leitura e análise de algumas obras selecionadas destes dois autores (FREIRE, 1981; 1987; 1996; 2015; SHIVA, 1993, 1995, 2003, 2005, 2006) propomos alguns temas (ou categorias) para se pensar os desafios encarados pela Educação Ambiental e pelos grupos subalternizados em resistência. Temas que não seriam possíveis se não fosse o encontro entre Freire e Shiva, o diálogo, que por mais que não tenha acontecido em vida, propomos que possa acontecer no plano das ideias e das utopias.

Nosso percurso se inicia com uma pequena apresentação dos dois pensadores, em que abordamos a importância de Paulo Freire e sua obra para a Educação Ambiental brasileira e a inserção de Vandana Shiva como uma das pioneiras na elaboração de uma ecologismo popular com grande influência da perspectiva das mulheres do Sul global. Depois adentramos as possibilidades de diálogo, não apenas entre algumas das principais categorias trabalhadas nas obras destes autores, mas também entre suas trajetórias de vida e a influência destas em seu pensamento. A partir daí, traçamos paralelos com aquilo que vimos compreendendo como uma Educação Ambiental desde el Sur.

\section{PAULO FREIRE E A EDUCAÇÃO AMBIENTAL}

O referencial teórico metodológico de Paulo Freire vem sendo amplamente utilizado por pesquisadores e educadores, no campo da Educação Ambiental (DELIZOICOV; DELIZOICOV, 2014). A Educação Ambiental Crítica, desde sua origem, teve forte influência na Educação Popular freiriana. Durante o período de redemocratização no Brasil, no final dos anos 1980, o diálogo entre ambientalistas, educadores populares e movimentos sociais levantaram a necessidade de se tratar a questão ambiental de forma politizada e não apenas pela ótica conservacionista, que dominava o ambientalismo recém-chegado ao Brasil, vindo dos países do norte. Nesse processo, as contribuições das teorias críticas da educação e do acúmulo trazido pelas organizações populares ajudaram a elaborar os ideais emancipatórios por essa vertente da educação ambiental (LOUREIRO, 2009). 
Ensino, Saúde e Ambiente - v. 14 n. esp. (2021): Dossiê Paulo Freire para além dos 100 anos: construir utopias, transformar a realidade, p. 512-535.

\section{Questão Ambiental e Promoção da Saúde}

Para Figueiredo (2006) a perspectiva de Paulo Freire oferece a possibilidade de elaboração de uma Educação Ambiental Dialógica, na medida em que enfatiza a dimensão do "ser mais" como vocação ontológica de todo ser humano. Além disso, o aprendizado só acontece se for coletivo, onde, a partir da superação das situações limitantes, os grupos caminham juntos, passando da curiosidade do senso comum para a "curiosidade epistêmica", aumentando sua criticidade e educando-se à medida que se percebem como sujeitos de sua história. Este autor salienta ainda que a perspectiva freiriana nos atenta para a necessidade de evitar os discursos vazios, demagógicos e descolados da prática, tão comuns na Educação Ambiental em suas vertentes mais pragmáticas ${ }^{2}$, pois como apresenta Freire, a palavra se torna potente quando se transforma em "palavra- ação" (FIGUEIREDO, 2006).

Camargo e Sánchez (2015) argumentam que a metodologia freiriana é especialmente importante na contextualização das práticas educativas ambientais, pois parte dos saberes e realidades locais para ampliar o olhar sobre as questões ambientais mais urgentes, favorecendo o diálogo entre diferentes saberes. Para os autores, essa dinâmica potencializa o engajamento das comunidades nos projetos de transformação socioambiental, pois considera sua realidade concreta como ponto de partida para o aprofundamento das dinâmicas ambientais, políticas, sociais e culturais que compõem a realidade.

O Grupo de Estudos em Educação Ambiental desde el Sur (GEASur), destaca, que para a Educação Ambiental de base Comunitária (EABC) o diálogo entre a Educação Ambiental e a Educação Popular freiriana assume um papel central (CAMARGO, 2017; OLIVEIRA; SÁNCHEZ, 2018). Isso porque, em muitas experiências, o diálogo de saberes, a memória oral, as histórias de vida, a cultura popular e os saberes locais vêm constituindo bases férteis para estruturação de propostas educativas comunitárias e territorializadas. Da mesma forma, observa-se a necessidade de diálogo com a dimensão imaterial das relações ser humanonatureza, no que diz respeito à espiritualidade e a transcendência (CAMARGO, 2017). Para a EABC, o acúmulo trazido por Paulo Freire, em constante diálogo com a caminhada das classes populares, compõe o legado produzido pelo pensamento crítico latino-americano. Por isso, seu pensamento consiste não apenas numa referência teórica para pesquisas e práticas, mas também

\footnotetext{
2 Assim como Layrargues e Lima (2014) compreendemos que não há uma só Educação Ambiental, mas que este é um campo heterogêneo onde algumas macrotendências principais podem ser destacadas - a conservacionista, a crítica e a pragmática. A corente pragmática seria aquela mais adaptada aos ditames do mercado, ligada à noção de desenvolvimento sustentável, das tecnologias e selos verdes, da eco- eficiência e da monetarização das emissões de gases).
} 
Ensino, Saúde e Ambiente - v. 14 n. esp. (2021): Dossiê Paulo Freire para além dos 100 anos: construir utopias, transformar a realidade, p. 512-535.

\section{Questão Ambiental e Promoção da Saúde}

como fundamentação filosófica, epistêmica e metodológica para se pensar a Educação Ambiental (SARRIA et. al., 2018).

Como reflete Layrargues (2014) a importância de Paulo Freire para a Educação Ambiental se deve à possibilidade de retomada da criticidade deste campo:

Mas por que, afinal de contas, Paulo Freire é uma referência fundamental para a Educação Ambiental? Talvez porque essa seja uma excepcional porta de entrada teórica para quem se inicia no campo, em função da sua vocação problematizadora cujo potencial de rompimento definitivo com o senso comum já cristalizado em uma Educação Ambiental conteudista, normativa, instrumental, acrítica, etapista e ahistórica, ideologicamente neutra não é nada desprezível. Talvez também porque oportuniza, a todos os educadores ambientais que minimamente reconhecem no pensamento freiriano as possibilidades de enfrentamento e superação das formas de opressão, controle e poder autoritário, as condições político-pedagógicas para o adensamento das forças sociais progressistas (LAYRARGUES, 2014, p. 11-12).

\section{VANDANA SHIVA E O AMBIENTALISMO POPULAR IMPULSIONADO PELAS MULHERES}

A figura de Vandana Shiva como ativista ambientalista é hoje reconhecida mundialmente. Nascida na cidade indiana de Dehra Dun, bem abaixo dos Himalaias, filha de mãe agricultora e pai guarda florestal, graduou-se em física, cursou o mestrado em filosofia da ciência, e fez o doutorado na área da física quântica. Seu direcionamento para as questões ambientais, segundo ela, se deu na volta para casa, onde percebeu com tristeza a degradação e a pobreza nas regiões onde vivia quando criança (SHIVA, 1995). Seu envolvimento com o movimento Chipko $^{3}$, articulado por grupos de camponesas indianas, marcou fortemente sua produção teórica e seu ativismo. Para Jacob (2019):

[...] Vandana Shiva combina aguçada pesquisa intelectual com corajoso ativismo e suas ações abrangem desde incansáveis conferências em universidades de todo o mundo até à interação com camponeses e camponesas na zona rural da Índia. Como intelectual militante, Shiva atua em muitas frentes e seu trabalho tem enorme

\footnotetext{
${ }^{3}$ O Movimento Chipko (palavra indiana que significa "abraço") foi um movimento de resistência liderado por um grupo de camponesas indianas de Uttarakhand, nos anos 1970, contra o desmatamento voltado para extração de madeira, em bosques milenares, dos quais dependia sua sobrevivência e de sua comunidade. $\mathrm{O}$ ato de abraçar as árvores para impedir que fossem derrubadas ganhou repercussão em todo mundo. Além da preservação florestal, as mulheres denunciavam a imposição de um modelo que transformava a complexidade e multifuncionalidade da floresta para as comunidades em simples fornecedora de matéria prima para o capital privado (SHIVA, 1995).
} 
Ensino, Saúde e Ambiente - v. 14 n. esp. (2021): Dossiê Paulo Freire para além dos 100 anos: construir utopias, transformar a realidade, p. 512-535.

\section{Questão Ambiental e Promoção da Saúde}

repercussão tanto no Norte quanto no Sul global. Uma pluralidade de movimentos locais e globais encontram em Vandana Shiva elementos teóricos e impulso inspirador para levarem adiante suas lutas em defesa das sementes crioulas, pela propriedade tradicional do conhecimento, contra o patriarcado e pela soberania alimentar (JACOB, 2019, p. 1).

A amplificação da noção de ecologia, para abrigar não apenas as riquezas naturais, mas também os setores marginalizados da sociedade fazem parte do pensamento de Shiva (KOTHARI, 1995). Além disso, em suas obras, é possível perceber a constante articulação entre os fenômenos locais (expropriação da terra, fome e insegurança alimentar, imposição de modelos de produção insustentáveis, privatização da água) e as determinações geopolíticas globais para os países empobrecidos. ${ }^{4}$ (SHIVA, 1995, 2003, 2006).

Ao salientar a importância de se analisar a crise ambiental a partir do ponto de vista das mulheres do Sul global, Shiva representa uma voz eloquente dentro do pensamento Ecofeminista, que dá foco à resistência das mulheres sob uma perspectiva descolonizadora e empoderadora (KIRJNER, 2019). Para a autora, o combate ao universalismo é também o combate à violência que opera através da invisibilização, por um lado, do trabalho e das redes de produção de vida, mantidas pelas mulheres; por outro, dos impactos do "desenvolvimento", que recaem de forma mais intensa sobre elas e seus filhos, à medida que devastam as fontes de subsistência e a sociobiodiversidade (MIES; SHIVA, 1993; SHIVA, 2003).

As discussões levantadas por Shiva encontram ressonância também na Ecologia Política (MARTÍNEZ ALIER, et. al., 2017) e da Educação Ambiental (OLIVEIRA et. al., 2020). A percepção dos conflitos ambientais como pontos chave para o desvelamento das assimetrias no acesso, gestão e uso das riquezas naturais pelos diferentes grupos sociais, faz parte do esforço empenhado por estes campos (LOUREIRO; LAYRARGUES, 2013). Sob a perspectiva da Educação Ambiental de base Comunitária (EABC) experiências como a dos movimentos sociais, comunidades tradicionais, organizações populares, conselhos comunitários, grupos de mulheres, entre outros, representam formas de resistências ambientais populares, que vêm gestando alternativas coletivas para o enfrentamento das questões socioambientais, partindo do diálogo com a Educação Popular e a Ecologia de saberes (SARRIA et. al. 2018). Nesse escopo, categorias trazidas por Shiva, como "monocultura das mentes", "mau desenvolvimento",

\footnotetext{
${ }^{4}$ Nesse sentido, podemos citar como exemplos o modelo de desenvolvimento capitalista e a revolução verde, como formas impostas pelos países ricos como solução para o subdesenvolvimento e a fome. Projetos que, como argumenta Shiva, acabaram por intensificar esses processos, à medida que desmantelaram modos de vida e economias de subsistência e restringiam a soberania alimentar das comunidades, respectivamente (SHIVA, 2003). 
Ensino, Saúde e Ambiente - v. 14 n. esp. (2021): Dossiê Paulo Freire para além dos 100 anos: construir utopias, transformar a realidade, p. 512-535.

\section{Questão Ambiental e Promoção da Saúde}

"enraizamento" nos auxiliam a aprofundar nosso entendimento sobre do chamando “ecologismo popular" (ALIMONDA, 2014) tanto no âmbito teórico acadêmico, quanto na prática educativa engajada junto às comunidades.

As contribuições de Shiva também dão suporte teórico/prático para o fortalecimento de movimentos como a agroecologia, o movimento por soberania alimentar e a luta contra os transgênicos (JACOB, 2019). A partir de uma crítica radical à crise ambiental, como resultado da dominação e colonização das fontes regeneradoras de vida, pelo capitalismo patriarcal, Shiva lança mão de uma ótica ecofeminista do Sul, anti- colonialista e anti- capitalista, para pensar e pôr em prática $^{5}$ alternativas que produzem epistemologias outras, outras formas de estar no mundo.

\section{DIÁLOGOS ENTRE PAULO FREIRE E VANDANA SHIVA}

\section{A IDENTIFICAÇÃO DAS OPRESSÕES}

Analisar a realidade sob uma perspectiva crítica significa interpretá-la como resultado de múltiplos fatores. Significa também identificar e esmiuçar as estruturas não aparentes de poder que estão por trás daquilo que entendemos como real. A identificação das opressões, suas causas e desdobramentos em nossa realidade social, política, cultural e ambiental, ao longo da história, são parte desse esforço. É nessa esteira que traçamos um primeiro ponto de encontro entre o pensamento de Vandana Shiva e Paulo Freire.

O pensamento ambientalista de Vandana Shiva se distancia dos moldes hegemônicos ocidentais, exatamente por questionar as causas que interligam a degradação ambiental às injustiças sociais, nos países do Sul global. Sua principal crítica se destina à culpabilização dos pobres e dos países subdesenvolvidos como principais responsáveis pela degradação ambiental no planeta (SHIVA, 1995). Apoiada pela experiência indiana, a autora expõe a crise ambiental como resultado de um sistema monocultural capitalista e patriarcal, que é ambientalmente destrutivo e socialmente excludente. E aponta o colonialismo, o imperialismo e, mais recentemente, o desenvolvimento capitalista como processos produtores de pobreza e degradação ambiental, na medida em que vêm contribuindo substancialmente para o

\footnotetext{
${ }^{5}$ A organização Navdanya, fundada por Vandana Shiva, tem como objetivo a preservação das sementes, do solo, das águas e dos conhecimentos tradicionais sob uma perspectiva alternativa. Para saber mais: 
Ensino, Saúde e Ambiente - v. 14 n. esp. (2021): Dossiê Paulo Freire para além dos 100 anos: construir utopias, transformar a realidade, p. 512-535.

\section{Questão Ambiental e Promoção da Saúde}

desmantelamento das redes de produção de vida e subsistência desses povos, ao longo do tempo. Dessa forma, a questão ambiental pode ser enxergada sob a perspectiva da produção de opressões, a partir das disputas entre os interesses dos grupos populares e do capital privado nos territórios.

Na teoria e prática político- pedagógicas elaboradas por Paulo Freire, a dimensão da opressão assume um papel central. Em sua "pedagogia do oprimido" Freire (1987) aprofunda a origem das opressões como causa da desumanização imposta aos oprimidos por aqueles que compõem as classes dominantes. Concebe, portanto, a humanização como vocação de todos os seres humanos e sua oposta, a desumanização, como realidade histórica em que essa vocação é negada, a partir das injustiças e da opressão. Salienta que, por ser histórica tal realidade não é definitiva e pode, portanto, ser transformada. Daí o fato da situação de opressão ser também impulsionadora da luta pela liberdade, pela desalienação, pelo fim da própria opressão. Assim, a pedagogia do oprimido é concebida como:

[...]aquela que tem de ser forjada com ele e não para ele, enquanto homens ou povos, na luta incessante de recuperação de sua humanidade. Pedagogia que faça de sua opressão e de suas causas objeto da reflexão dos oprimidos, de que resultará o seu engajamento necessário na luta por sua libertação, em que esta pedagogia se fará e refará (FREIRE, 1987, p. 32).

Materialmente, as relações de opressão se manifestam de diversas formas e são inauguradas, segundo Freire, pelo opressor, por meio da violência presente na negação à palavra do oprimido, por sua objetificação, através do roubo de seu trabalho, do impedimento de que tenha uma vida digna. Aspectos que nos aproximam também das injustiças ambientais que acabam por restringir formas de vida que não se adéquam ao modelo moderno ocidental, obrigando populações que mantém relações de interdependência e subsistência com a natureza por gerações a, simplesmente, abandonar seus saberes e modos de vida e incorporar modelos estrangeiros desenvolvimentistas que se impõem violentamente nos territórios, mesmo que estes lhes arrastem para a escassez, proveniente da falta de autonomia sobre o trabalho, a terra e o saber (SHIVA, 2003). Como reitera Freire (1987) os opressores tendem a perpetuar esse modelo, que passa de geração a geração.

[...] Daí que tendam a transformar tudo o que os cerca em objeto de domínio. A terra, os bens, a produção, a criação dos homens, os homens mesmos, o tempo em que estão os homens, tudo se reduz a objeto de seu comando. Nessa ânsia irrefreada de posse, 
Ensino, Saúde e Ambiente - v. 14 n. esp. (2021): Dossiê Paulo Freire para além dos 100 anos: construir utopias, transformar a realidade, p. 512-535.

\section{Questão Ambiental e Promoção da Saúde}

desenvolvem em sai a convicção de que lhes é possível transformar tudo a seu poder de compra. Daí a sua concepção estritamente materialista da existência. O dinheiro é a medida de todas as coisas. E o lucro seu objetivo principal (FREIRE, 1987, p. 46).

Shiva (1995), por sua vez, localiza essa lógica como fundante do sistema capitalista patriarcal ocidental e reflete sobre suas consequências sobre as relações com a natureza e o conhecimento:

La revolución científica de Europa transformó la naturaleza de terra mater en una máquina y una fuente de materias primas; con dicha transformación quedaron eliminadas todas las limitaciones éticas y cognocivas que impedían violentarla y explotarla. La revolución industrial convirtió la economia de prudente administración de los recursos para el sustento y satisfacción de las necesidades básicas en un proceso de producción de bienes para hacer el máximo de ganancias. El industrialismo creó un ilimitado apetito de explotación de recursos, y la ciencia moderna proporcionó la licencia ética y cognociva para que dicha explotación fuera posible, aceptable y deseable (SHIVA, 1995, p. 23).

A reflexão trazida por Shiva com respeito à utilização da ciência e do conhecimento como formas de dominação é compartilhada por Freire, quando reflete sobre o alcance da lógica opressora:

Na medida em que, para dominar, se esforçam por deter a ânsia de busca, a inquietação, o poder de criar, que caracterizam a vida, os opressores matam a vida. Daí que vão se apropriando, cada vez mais, da ciência também, como instrumento para suas finalidades. Da tecnologia, que usam como força indiscutível de manutenção da "ordem" opressora, com a qual manipulam e esmagam (FREIRE, 1987, p. 47).

No campo da educação ambiental, uma das principais críticas feita pela EAC e pela EABC à vertente pragmática ${ }^{6}$ é sua "neutralidade", ou, poderíamos dizer, sua "universalidade". A disseminação da mensagem ambiental por órgãos internacionais, pelas mídias e por programas empresariais, na maioria das vezes, traz essa visão uniformizada de comportamentos e práticas adequados à preservação ambiental e à sustentabilidade. O que pouco de discute é a falta de interlocução com a realidade local das comunidades, com as disputas econômicas e políticas em torno doa acesso e gestão das riquezas ambientais e da real responsabilidade dos 
Ensino, Saúde e Ambiente - v. 14 n. esp. (2021): Dossiê Paulo Freire para além dos 100 anos: construir utopias, transformar a realidade, p. 512-535.

\section{Questão Ambiental e Promoção da Saúde}

grandes empreendimentos na degradação dos territórios e dos bens naturais comuns, em benefício de interesses privados (LAYRARGUES; LIMA, 2014).

O diálogo entre as perspectivas de Shiva e Freire nos trazem instrumentos para problematizar a universalidade e a neutralidade do pensamento ambiental contido na Educação Ambiental hegemônica. Como afirma Shiva (2003), narrativas universalizantes e não politizadas acabam por encobrir a complexidade da questão ambiental e restringi-la à responsabilidade individual, desvinculando-a dos processos mais amplos como, por exemplo, o papel de produtores de matérias primas, destinado aos países do Sul, na geopolítica global. A pretensão de universalidade encobre o fato de que todo pensamento é localizado, mesmo o pensamento hegemônico, que se insere na lógica capitalista dos países ricos do Norte global e oferece subsídios para elaboração de um modelo para as políticas ambientais em todo mundo. Nessa se admite, por exemplo, que impactos socioambientais de grande magnitude, contra populações locais sejam encarados como "externalidades" do processo de produção capitalista e que a solução para elas esteja no oferecimento de medidas compensatórias e metas de "sustentabilidade" das empresas (MIES; SHIVA, 1993). Shiva nos alerta para a necessidade de contestação tanto da universalidade, quanto da neutralidade dos saberes e das condutas ambientais:

A ligação entre saber e poder é inerente ao sistema dominante porque, enquanto quadro de referência conceitual está associado a uma série de valores baseados no poder que surgiu com a ascensão do capitalismo comercial. A forma pela qual esse saber é gerado, estruturado e legitimado e a forma pela qual transforma a natureza e a sociedade geram desigualdades e dominação e as alternativas são privadas de legitimidade. O poder também é introduzido na perspectiva que vê o sistema dominante não como uma tradição local globalizada, mas como uma tradição universal, inerentemente superior aos sistemas locais (SHIVA, 2003, p. 22).

Freire (1996), por sua vez, quando se refere ao compromisso dos educadores progressistas e da própria educação libertadora argumenta que não se deve seguir o caminho da neutralidade, que em sua aparência externa parece não representar posicionamento algum, mas que na verdade representa sim o alinhamento com a conduta já estabelecida, geralmente, afinada aos interesses das classes dominantes. Para ele, o educador precisa manter claro para si e seus educandos o posicionamento político contrário às discriminações, às injustiças e a exploração das minorias, que são, na verdade, a maioria (FREIRE, 1996). 
Ensino, Saúde e Ambiente - v. 14 n. esp. (2021): Dossiê Paulo Freire para além dos 100 anos: construir utopias, transformar a realidade, p. 512-535.

\section{Questão Ambiental e Promoção da Saúde}

No que tange às discussões ambientais, poderíamos argumentar que o não posicionamento de ativistas, educadores e universidades com relação às injustiças ambientais vividas por grande parte da população do nosso país tende a manter o que já existe, um modelo de Educação Ambiental alienado de questões urgentes como: a fome, a perseguição de defensores dos direitos humanos e da natureza, a perda de territórios pelas populações tradicionais, a falta de condições ambientais básicas para a sobrevivência, entre outros.

Podemos perceber que, tanto Freire quanto Shiva nos fazem o convite de pensar para além do stablishment, do discurso oficial, do pensamento hegemônico. Suas reflexões nos impelem a enxergar a existência em sua complexidade, dialogicidade e historicidade, à medida que põe em discussão as bases filosóficas, sociais e políticas que estão por trás da opressão e que operam mecanismos não aparentes de dominação, tanto social quanto ambiental. Oferecem, portanto, pontos de partida para se pensar criticamente a relação ser humano- natureza, no sentido da desalienação.

\section{A CULTURA POPULAR E OS SABERES ANCESTRAIS}

Outro ponto de diálogo entre Paulo Freire e Vandana Shiva se encontra na forma como constroem seu pensamento: vinculando sempre teoria e prática. Assim que suas elaborações trazem consigo uma longa experiência junto aos grupos populares e suas situações concretas de vida. Se para Freire, essa experiência teve como ponto de partida o trabalho pedagógico junto aos agricultores, operários e muitos outros grupos populares em processos de alfabetização; para Shiva esse encontro se deu em meio ao ativismo socioambiental dos grupos camponeses em defesa de seus territórios e de suas formas de vida, especialmente no movimento Chipko, liderado pelas mulheres, na região dos Himalaias, na Índia.

Esse contato, constante em suas trajetórias de vida, transparece em seus escritos de uma forma muito particular, no sentido de que, mesmo não pertencendo àquela classe, ou aqueles grupos com os quais trabalham, se colocam, além de educadores, como aprendizes compromissados $^{7}$. Essa perspectiva parece refletir a convicção de que o saber não pode estar desvinculado da prática, muito menos da dimensão do coletivo, caso contrário, corre o risco de conduzir a práticas alienadas, descoladas da realidade. Nesse sentido, a produção de um saber

\footnotetext{
7 Aqui ressaltamos que a família de Paulo Freire, durante sua infância e adolescência, enfrentou sérias dificuldades financeiras. Freire conheceu a fome, que o marcou profundamente e foi definida por ele em algumas de suas obras como “expressão máxima das injustiças humanas” (MACHADO, 2015, p. 202).
} 
Ensino, Saúde e Ambiente - v. 14 n. esp. (2021): Dossiê Paulo Freire para além dos 100 anos: construir utopias, transformar a realidade, p. 512-535.

\section{Questão Ambiental e Promoção da Saúde}

engajado, voltado para a liberdade e para luta contra as injustiças não pode ser produzida sem a participação daqueles que as sofrem. Nesse ponto, Freire e Shiva percebem nos grupos oprimidos e naqueles mais atingidos pelas injustiças ambientais os principais agentes de transformação da realidade, respectivamente.

É nesse sentido que observamos em Freire a valorização da cultura popular como território de produção de saberes, de cultura e de leituras de mundo, tida como campo fértil de possibilidades para o processo educativo que leva ao "ser mais" (FREIRE, 1987). De forma semelhante, Shiva localiza nos saberes ancestrais, inseridos também na cultura de cada povo, as potencialidades para o aprendizado de relações ambientais e sociais mais harmônicas e menos destrutivas, reconhecendo que estes resultam de séculos de interações das comunidades humanas com a natureza (SHIVA, 2003).

Shiva identifica no reducionismo científico uma chave importante para se entender o apagamento dos saberes ancestrais, ao longo dos processos de imperialismo e do próprio "desenvolvimento" contemporâneo. Segundo ela, originária da revolução industrial entre os séculos XV e XVI, a lógica reducionista se inseriu perfeitamente nos desígnios do capitalismo industrial, ou seja, uma forma particular de organização política e econômica que tinha como base a homogeneização da produção, a fragmentação do conhecimento e a transformação da natureza em fornecedora de recursos naturais unifuncionais.

Essa lógica, desde o início, foi legitimada pela ciência reducionista que, de certa forma, transformou o conhecimento em especialidade e aqueles que os possuíam, em especialistas (SHIVA, 1993). Assim, toda forma de conhecimento que não se encaixasse nesse modelo passou a não ser encarada como conhecimento legítimo, mas como ignorância ou superstição. A partir daí, sistemas complexos de conhecimentos e tecnologias desenvolvidas pelos povos, baseados numa perspectiva holística de relação com a natureza, foram invisibilizados e classificados como não saber. ${ }^{8}$ Áreas florestadas e biodiversas, fruto do trabalho social destes grupos humanos, passaram a ser concebidas como natureza passiva, selvagem e improdutiva, sujeita à dominação e à exploração. Nesse fragmento, Shiva (1993) explica como este processo está no cerne da produção de injustiças e, poderíamos complementar, dos conflitos ambientais:

Quando o labor é definido como não- labor, o valor torna-se não valor, os direitos não direitos e a invasão passa a ser definida como um melhoramento. [...] Isso consegue três coisas simultaneamente: 1) nega qualquer contributo por parte daqueles cujos produtos são apropriados e, ao converter a sua actividade em passividade, transforma

8 Dinâmica que, na América Latina, remete à chegada dos primeiros invasores europeus (LEFF, 2009). 
Ensino, Saúde e Ambiente - v. 14 n. esp. (2021): Dossiê Paulo Freire para além dos 100 anos: construir utopias, transformar a realidade, p. 512-535.

\title{
Questão Ambiental e Promoção da Saúde
}

recursos utilizados e desenvolvidos em recursos "inutilizados", "não desenvolvidos" e "desperdiçados"; 2) ao interpretar a apropriação como "desenvolvimento" e "melhoramento", transforma o roubo num direito que reclama a propriedade, baseado numa alegação de melhoramento; e 3) da mesma maneira, ao definir o labor social anterior como natureza, não lhe conferindo, assim, quaisquer direitos, transformam os direitos que as pessoas reclamam como consuetudinários, de usufruto coletivo, em "pirataria" e roubo" (SHIVA, 1993, p. 49).

Ao discutir a importância da cultura popular dentro de um projeto educativo emancipatório, Freire reitera a produção de cultura como atividade humana fundamental de transformação do mundo, através do trabalho, mediada pela natureza. Discute também as relações de poder advindas dessa prática, na medida em que podemos identificar a existência de uma "cultura dominante" que se apresenta como universal e acaba por desconsiderar a produção de cultura pelos grupos subalternizados (FREIRE, 1981). Nesse sentido, nos ajuda a síntese de Brandão (2015):

\begin{abstract}
A oposição estrutural entre modos sociais de participação na cultura é o que explica a cultura popular. No contexto das sociedades latino-americanas, por exemplo, esta é uma das faces da relação negada de universalização da cultura, e torna mais do que visíveis a posição subalterna de saberes, valores e símbolos de sujeitos e grupos étnicos e sociais dominados no processo da história. Assim, as culturas dos dominados são, ao mesmo tempo, a cultura imposta às classes populares, e as culturas que elas criam de acordo com a forma como participam na vida social em todas as suas dimensões. (BRANDÃO, 2015, p. 120).
\end{abstract}

No âmbito da alfabetização de grupos camponeses, em vários países da América Latina, a crítica de Freire se volta para a forma como o analfabetismo era visto pelo pensamento dominante, como mazela a ser eliminada rapidamente e dos analfabetos como incapazes, como seres diferentes de todos os outros. Nesse mesmo sentido, o educador contestava a utilização de métodos pedagógicos depositários, conteudistas e infantilizadores, que desconsideravam totalmente a experiência existencial e o acúmulo de conhecimentos destes sujeitos, ao longo de sua vida. É dessa forma que seu método pedagógico buscou incorporar essas experiências, a partir da cultura popular, para que as palavras aprendidas tivessem significado em sua práxis e o movimento de aprendizado contribuísse para a percepção crítica dos educandos quanto a sua própria existência e sua atuação no mundo.

O Método Paulo Freire de alfabetização e educação de adultos realiza-se em uma geometria didática com pessoas ao redor de um círculo de cultura. E ele se inicia com 
Ensino, Saúde e Ambiente - v. 14 n. esp. (2021): Dossiê Paulo Freire para além dos 100 anos: construir utopias, transformar a realidade, p. 512-535.

\section{Questão Ambiental e Promoção da Saúde}

um diálogo em que, através de sucessões de imagens sugestivas, os educandos se descobrem como seres do mundo da cultura. Um mundo criado por eles por meio do trabalho, da práxis. Um mundo que, portanto, uma vez dialogado, refletivo e criticamente repensado e passado da "consciência ingênua" à "consciência crítica", deveria ser social e politicamente transformado. Como um dos principais pensadores dos movimentos de cultura popular e da pedagogia crítica situada em uma proposta de educação libertadora, Paulo Freire foi sempre um defensor da ideia de que existe uma dimensão política na cultura e, portanto, na educação (BRANDÃO, 2015, p. 116).

Quando nos voltamos para Educação Ambiental, os aspectos levantados pelos dois autores dão embasamento teórico/prático para compreendermos os grupos populares como produtores de conhecimentos e de formas de relação com a natureza, que estão interconectadas à produção de cultura. As dimensões social e ambiental aparecem, portanto, indissociáveis.

No Brasil e em toda América Latina, a ambientalização das lutas sociais vem se dando através da luta pela terra, contra a mineração e a privatização da água, pela soberania alimentar, entre outros. Movimentos frequentemente impulsionados pelas mulheres e suas comunidades, cuja ligação com o trabalho de subsistência as tornam mais dependentes das riquezas naturais comuns (SVAMPA, 2015). A Marcha das Margaridas, que acontece no Brasil há alguns anos, é um exemplo da articulação entre diferentes reivindicações trazidas pelas mulheres do campo, das águas e das florestas, onde a temática ambiental se mostra cada vez mais presente como parte estratégica da resistência e permanência das comunidades em seus territórios (SILIPRANDI, 2012). A experiência dessas mulheres, de luta e busca por alternativas contra a fome e as injustiças produzem aprendizados, práticas e valores que enriquecem a perspectiva da Educação Ambiental (OLIVEIRA et. al., 2020).

Estas constatações reforçam a importância de se buscar nas lutas e resistências socioambientais populares a real potencialidade de transformação das relações sociais, culturais e ambientais. Da mesma forma, o compromisso da Educação Ambiental com a visibilização, reflexão e aprendizado crítico, a partir destas resistências, se torna fundamental para a o processo de aumento da criticidade dos indivíduos sobre sua própria realidade ambiental e da sociedade como um todo (LOUREIRO, 2009). O reconhecimento de que os grupos populares vêm produzindo conhecimentos e relações ambientais diversas, a partir do seu trabalho de subsistência, em constante diálogo com os ciclos da natureza (SHIVA, 2003); se fortalece com a existência de dinâmicas pedagógicas que produzem reflexões sobre as injustiças ambientais e a disputa de interesses por trás delas e, sobretudo, que possibilitam a conscientização destes grupos sobre sua atuação como transformadores dessa realidade. 
Ensino, Saúde e Ambiente - v. 14 n. esp. (2021): Dossiê Paulo Freire para além dos 100 anos:

construir utopias, transformar a realidade, p. 512-535.

Questão Ambiental e Promoção da Saúde

\section{A SOCIOBIODIVERSIDADE COMO TERRENO FÉRTIL PARA OS INÉDITOS VIÁVEIS}

Da mesma forma que podemos observar o empenho crítico de desvelamento das injustiças, tanto em Freire como em Shiva, encontramos também em suas concepções o que Freire (1987) identifica como "anúncio". Em uma de suas obras (FREIRE 2015) ele reflete sobre a ineficiência do pensamento (ou do intelectual) que apenas critica sem se empenhar na busca por possibilidades de anúncio; sem dialogar com a historicidade dos processos humanos, que estão em constante modificação: "Seres condicionados não determinados, nossa luta constante, ou uma delas, se faz no sentido de não sermos reduzidos ao papel de puros objetos, como se não tivéssemos transformado o suporte em mundo.” (FREIRE, 2015, p. 19).

Assim que, para Freire, diante do olhar histórico para os processos, as possibilidades de libertação surgem a partir da tomada de consciência de que a realidade concreta, apesar de limitante, não é definitiva. Dessa forma, os próprios limites, quando conhecidos e refletidos criticamente, podem servir como impulsionadores do engajamento de mulheres e homens em ações libertadoras (FREIRE, 1987). Em seu método pedagógico este fundamento se materializa na identificação das "situações- limites" e, a partir delas, na possibilidade de se pensar "inéditos viáveis”. À medida que as limitações são analisadas sob uma perspectiva cada vez mais crítica, é possível abrir espaço para a imaginação de novas possibilidades, de alternativas possíveis para aquele grupo, naquele momento histórico, o que possibilita a superação da situação paralisadora e o caminhar no sentido da ação social (ibid.).

Da mesma forma que Freire enxerga nos grupos populares a potencialidade libertadora tanto para oprimidos como para opressores (FREIRE, 1987), Shiva compreende que o fortalecimento das mulheres, das comunidades tradicionais e a garantia de continuidade de seus modos de vida são a chave para que toda humanidade aprenda outras formas de relação entre as pessoas e com a natureza.

Em seu livro "Monoculturas da mente" Shiva (2003) discorre sobre uma de suas teorias mais conhecidas: a monocultura como silenciadora de alternativas e destruidora da diversidade. O modelo civilizatório imposto aos países colonizados (e a todo mundo, através da globalização capitalista) tem um caráter homogeneizador e uma das formas pela qual constrói essa homogeneidade fictícia é através da eliminação da diversidade, tanto da diversidade cultural e cognitiva (saberes, conhecimentos, epistemologias) quanto da diversidade biológica. 
Ensino, Saúde e Ambiente - v. 14 n. esp. (2021): Dossiê Paulo Freire para além dos 100 anos: construir utopias, transformar a realidade, p. 512-535.

\section{Questão Ambiental e Promoção da Saúde}

Consequentemente, a monocultura consiste sim num modo de produção agrícola que soterrou a complexidade das práticas milenares locais, trazendo escassez nutricional e pobreza. Mas mais do que isso, o pensamento monocultural também passou a povoar as subjetividades, instituindo o saber único, o modelo social único, a forma de relacionar-se com a natureza única. Nesse cenário, o espaço para se pensar alternativas dentro da pluralidade e da diversidade é sistematicamente negado pela cultura dominante capitalista. A crise ambiental, portanto, se configura na negação da pluralidade e da sociobiodiversidade como potência criativa de renovação da vida (MIES; SHIVA, 1993).

Ao buscarmos aproximar o pensamento de Shiva e Freire, no que diz respeito à busca por alternativas ao modelo dominante, podemos compreender, que para ambos o ponto de partida é tudo aquilo que é e sempre foi negado. Ou seja, os grupos populares expropriados de sua relação de interdependência com a Terra, são aqueles que possuem a potencialidade de, ao reconhecerem e lutarem por sua humanidade, transformar as relações socioambientais na qual estão inseridos. Nesse percurso incessante de busca por alternativas, a diversidade aparece como elemento fundamental.

A sociobiodiversidade, ao contrário da homogeneização, oferece maior repertório, tanto concreto quanto subjetivo, para se pensar alternativas para os problemas cotidianos nos territórios e para a luta contra as injustiças. A biodiversidade garante a maior resiliência dos sistemas ecológicos e das comunidades humanas, ao passo que oferece alternativas acessíveis de subsistência e cura, mesmo àqueles excluídos do sistema dominante. Já a pluralidade das culturas traz consigo cosmovisões, tecnologias, experiências e práticas que engrossam o caldo das possibilidades de gestão coletiva das riquezas naturais e das resistências contra a privatização dos bens comuns (SHIVA, 2003, 2006).

Dialogando com a perspectiva de Freire, Loureiro (2019) ressalta que a Educação Ambiental Crítica não entende que a Educação Ambiental tem o papel de disseminar hábitos e valores, provenientes das classes dominantes, tidos como mais adequados ao enfrentamento da crise ambiental. Mas sim, possibilitar junto aos grupos populares, baseado em sua realidade e em suas formas de significação da natureza, o desenvolvimento de processos críticos que promovam sua maior participação e a construção de novas relações, desenvolvidas coletivamente. Nessa esteira, a diversidade de atores sociais, envolvidos nos processos pedagógicos ambientais se torna uma potência, onde a experiência das mulheres, dos povos indígenas, das comunidades camponesas, dos grupos periféricos e muito outros podem trazer 
Ensino, Saúde e Ambiente - v. 14 n. esp. (2021): Dossiê Paulo Freire para além dos 100 anos: construir utopias, transformar a realidade, p. 512-535.

\section{Questão Ambiental e Promoção da Saúde}

diferentes pontos de vista e contribuições para se pensar alternativas libertadoras (LOUREIRO; FRANCO, 2014).

Estas reflexões trazem para a Educação Ambiental a necessidade de integração entre os processos de humanização e a preservação da diversidade, que deixa de ser apenas biodiversidade para englobar a sociobiodiversidade. Percebendo os seres humanos, portanto, não como seres apartados da natureza, essencialmente destruidores e dominadores; mas como seres históricos em constante elaboração de sua existência, junto à natureza. Esta percepção não exclui os conflitos e as condutas de exploração ambiental, mesmo dos grupos populares, condicionadas também pela lógica dominante capitalista de mercantilização da vida. No entanto, nos permite percebê-los criticamente, como parte do movimento de busca por alternativas contra a opressão, a expropriação, o deplazamiento e as injustiças ambientais. Trajetória que, cada vez mais, evidencia a interdependência entre as dinâmicas sociais e ambientais, já que é na diversidade social e ambiental que se encontra a possibilidade de enfrentamento do sistema capitalista.

\section{EDUCAÇÃO AMBIENTAL DESDE EL SUR: PELA HUMANIZAÇÃO, DESALIENAÇÃO E INTERDEPENDÊNCIA}

De muitas formas Paulo Freire e Vandana Shiva nos auxiliam a pensar uma Educação Ambiental desveladora das estruturas opressoras, onde os grupos subalternizados assumem o papel negado de agentes das transformações socioambientais. A Educação Ambiental que nos chega de forma hegemônica, ainda estabelece a uniformidade dos conhecimentos ecológicos como base de compreensão das dinâmicas ambientais; quando estas, na verdade, se inserem numa complexa rede de interações sociais, culturais e políticas. Para Leff (2009) os "saberes ambientais" tão desejados para a transformação da sociedade não são predeterminados, nem se exaurem nas soluções tecnológicas, mas surgem da interação entre os atores sociais e a natureza em meio às disputas e aos imprevistos. São, portanto, saberes relacionais e inacabados.

Nesse sentido, quando apontamos para uma Educação Ambiental desde el Sur nos referimos às insurgências de movimentos e práticas que contestam o discurso único dos países centrais, para elaborar dinâmicas enraizadas nas realidades locais, na cultura popular, nas lutas dos povos originários e das comunidades tradicionais (SARRIA, et. al., 2018). Em outras palavras, experiências que geram conceitos, epistemologias e saberes que se constituem nas 
Ensino, Saúde e Ambiente - v. 14 n. esp. (2021): Dossiê Paulo Freire para além dos 100 anos: construir utopias, transformar a realidade, p. 512-535.

\section{Questão Ambiental e Promoção da Saúde}

resistências e, por sua vez, complexificam a visão ambiental ao trazê-la para realidade da periferia, dos invisibilizados, desde el Sur.

O ambientalismo disseminado por Vandana Shiva se insere na realidade sociocultural da Índia, país multidiverso que esteve por quase 90 anos sob o domínio imperialista inglês. Processo que teve como resultados a intensificação da exploração dos recursos naturais, o apagamento sistemático dos conhecimentos tradicionais e a disseminação da pobreza e da fome. Daí a urgência de um pensamento ambiental comprometido com a eliminação das desigualdades.

A relação entre os seres humanos e a natureza, na visão de Shiva, é fortemente influenciada pela fillosofia e a cosmologia indianas, onde esta última aparece como uma força criativa, um princípio sagrado e feminino (SHIVA, 1995), capaz de gerar e regenerar a vida em todas as suas formas. Essa noção de sacralidade da natureza se aproxima bastante da visão dos povos originários latino-americanos que enxergam na terra como Pacha Mama, a mãe sagrada e abundante. A autora salienta que uma das ferramentas mais poderosas de desestruturação das culturas e sociedades originárias, durante os diferentes processos de colonização, foi exatamente o desmantelamento e o apagamento das relações de sacralidade com a terra, onde a Mãe Terra foi substituída pelo deus cristão (SHIVA, 1995).

Para além da dimensão cosmológica indiana, Shiva também conecta sua discussão ambiental às dinâmicas de produção de injustiças através da invisibilização do trabalho de subsistência e de preservação das riquezas naturais realizado pelas populações tradicionais e pelas mulheres. Salienta que os impactos ambientais mais severos atingem de forma mais intensa as comunidades e as mulheres do Sul global. Daí que sua crítica se volta ao modelo de desenvolvimento que desconsidera outros modos de vida que não a capitalista ocidental e prioriza a economia financeira global em detrimento da qualidade de vida da maioria (MIES; SHIVA, 1993).

Por mais que Paulo Freire não tenha se debruçado diretamente sobre a questão ambiental, ou o ambientalismo, a relação "ser- humano- natureza" aparece constantemente em sua obra. Em seus primeiros escritos, há a menção da natureza como mediadora da ação transformadora de homens e mulheres no mundo, através do seu trabalho (FREIRE, 1981, 1987, 1996). Ao longo do tempo, em suas obras mais tardias essa relação se aprofunda, na medida em que a experiência com o território e com as próprias memórias aparecem como constitutivas da subjetividade e da identidade dos sujeitos. Assim que mulheres e homens transformam, mas também são transformados ao longo de suas vidas. 
Ensino, Saúde e Ambiente - v. 14 n. esp. (2021): Dossiê Paulo Freire para além dos 100 anos: construir utopias, transformar a realidade, p. 512-535.

\section{Questão Ambiental e Promoção da Saúde}

[...] O Brasil dificilmente existiria pra mim, na forma como existe, sem o meu quintal, a que se juntam ruas, bairros, cidades. A terra que a gente ama, de que a gente sente falta e a que se refere, tem sempre um quintal, uma rua, uma esquina, um cheiro de chão, um frio que corta, um calor que sufoca, um valor por que se luta, uma carência sentida, uma sobra que maltrata a carência, uma língua que se fala em diferentes entonações. A terra por que se dorme mal, às vezes, terra distante, por causa da qual a gente se aflige tem que ver com o quintal da gente, tem que ver com esquinas de ruas, com os sonhos da gente. Em certo momento a amorosidade por nosso quintal se estende ao bairro onde se acha a casa, vai se ampliando a outros bairros e termina por se alojar numa área maior a que nos filiamos e em que deitamos raízes, a nossa cidade (FREIRE, 2015, p. 21).

Esse enraizamento, de que nos fala Freire, tem grande conexão com a noção de território, trazida pelas lutas camponesas de reforma agrária. E de tantos outros movimentos socioambientais populares, que, ao enfrentarem a expropriação de suas terras e a migração forçada, oriundas da expansão de grandes empreendimentos privados, resignificam o sentido do território, sem o qual não há vida comunitária, produção de memórias, religiosidade e a própria reprodução da vida em todas as suas formas. O acompanhamento de Freire a grupos camponeses nos mais diversos territórios da América- Latina apresenta essa perspectiva a partir da relação com a terra, tida como bem comum, cuja função social se volta para produção de alimento e existências (FREIRE, 2015). Hoje, os índices de concentração fundiária latinoamericanos permanecem como um dos maiores do mundo (OXFAN, 2019), realidade que está por trás de grande parte dos conflitos socioambientais.

Shiva (1993) explora a questão do enraizamento como uma categoria produtora de resistências. Para ela, o desenvolvimento capitalista ocidental assume um caráter desenraizante, à medida que as empresas e conglomerados industriais, por exemplo, não pertencem especificamente a um território ou país, mas assumem uma identidade globalizada. Estas empresas, por sua vez, utilizam estratégias de desenraizamento das populações locais como forma de desarticulá-las e evitar os conflitos. Assim, suas relações com a terra, com o território e com a natureza são desconsideradas e suas vidas objetificadas.

O desenvolvimento tem significado a ruptura ecológica e cultural dos laços com a natureza, no seio da sociedade, a transformação de comunidades orgânicas em grupos de indivíduos desenraizados e alienados em busca de identidades abstratas. (SHIVA, 1993, p. 135) 
Ensino, Saúde e Ambiente - v. 14 n. esp. (2021): Dossiê Paulo Freire para além dos 100 anos: construir utopias, transformar a realidade, p. 512-535.

\section{Questão Ambiental e Promoção da Saúde}

Freire traz para esse diálogo a constatação de que a objetificação de homens e mulheres e da própria vida fazem parte das engrenagens da desumanização. Por isso, é tão importante que as pessoas tenham consciência destes processos, para que possam combatê-los. Objetificação que é contrária à amorosidade e à vocação de "ser mais". Pensar uma Educação Ambiental a partir dos aportes de Shiva e Freire, nesse sentido, significa desvelar constantemente os processos de desumanização intimamente interligados à destruição da natureza pelo pensamento dominante. Como argumenta Shiva, um dos caminhos para o enfrentamento da crise ambiental passa pela retomada da diversidade negada e pela conscientização de interrelação dos processos.

A “activação" do que foi, ou está a ser, interpretado como "passivo" pela sensibilidade patriarcal, torna-se então o passo mais significativo na renovação da vida. Superar a alienação dos ritmos e dos ciclos de renovação da natureza e participar neles conscientemente, torna-se uma fonte de activação enorme. [...] Essa procura e essa experiência da interdependência e da integridade são a base para a criação de uma ciência e conhecimento que, em vez de violar, estimula os sistemas sustentáveis da vida (SHIVA, 1993, p. 51).

Essa perspectiva aponta também para a interdependência dos processos ambientais, sociais, históricos e culturais; e para necessidade do olhar crítico para as dinâmicas que naturalizam a opressão, a exclusão e a exploração desenfreada das riquezas naturais e do trabalho humano. É dessa forma que a Educação Ambiental assume como base filosófica e epistêmica o compromisso com as populações vulnerabilizadas e empobrecidas, entendendo-as como sujeitas coletivas dos processos de transformação. Como argumenta Layrargues (2007), sem o olhar para as injustiças sociais, a Educação Ambiental abre mão de seu potencial revolucionário de produção de mudanças socioambientais significativas e acaba por assumir o papel de simples reprodutora social.

A desconexão entre sociedades e natureza, imposta pelo modelo capitalista patriarcal, produz visões de mundo individualistas, alienadas, consumistas, economicistas, racistas e preconceituosas. Essas visões influenciam diversos aspectos da vida, inclusive na forma como se concebe a Educação e a Educação Ambiental. O desafio para uma Educação Ambiental desde el Sur está, portanto, na contramaré, em que os coletivos populares e outros grupos comprometidos (diversos e plurais) insistem na valorização do comum, da cooperação, da simplicidade, da partilha, do bem viver. 
Ensino, Saúde e Ambiente - v. 14 n. esp. (2021): Dossiê Paulo Freire para além dos 100 anos: construir utopias, transformar a realidade, p. 512-535.

\section{Questão Ambiental e Promoção da Saúde}

\section{CONSIDERAÇÕES}

A busca por novas perspectivas teóricas e práticas para Educação Ambiental se torna urgente num momento em que setores conservadores tomam força e ameaçam tanto a democracia, quanto a soberania dos povos e da natureza. Inspirados por Freire, nos abrigamos no diálogo, no surgimento de novas possibilidades a partir do encontro, da troca e do compromisso atento com as questões de nosso tempo. Vandana Shiva e Paulo Freire nos ajudam a perceber algumas questões fundamentais, não apenas para se pensar estratégias de resistência socioambiental a partir do fortalecimento dos grupos populares e seus saberes; como também nos instigam a pensar em nossa existência neste planeta como parte de um processo inacabado de interdependência.

Seus aportes nos orientam no sentido da necessidade da criticidade e do comprometimento da Educação Ambiental com a perspectiva dos grupos subalternizados, cujas resistências vêm produzindo alternativas que se nutrem da sociobiodiversidade. Não é por acaso que estes grupos e a própria diversidade sejam os principais alvos da expansão do capital e do autoritarismo nos territórios. Apostar numa Educação Ambiental desde el Sur, no sentido que Freire e Shiva nos propõem, significa confiar na possibilidade de transformação da realidade limitante, partindo da abundância cultivada pelas culturas populares diversas e por mulheres e homens que teimam em não aceitar a escassez e a injustiça como realidades últimas.

\section{REFERÊNCIAS}

ALIMONDA, H. Una introducción a la ecología política latinoamericana (pasando por la historia ambiental). I Congreso Latinoamericano sobre Conflictos Ambientales y Curso Internacional sobre Ecología Política, 2014. Disponible en: http://www.ungs.edu.ar. Acesso: 23/03/2018.

BRANDÃO, C R. Cultura Popular. In: STRECK, Danilo R.; REDIN, Euclides; ZITKOSKI, Jaime J. (orgs.) Dicionário Paulo Freire. São Paulo: Autêntica, p. 118 - 121, 2015.

CAMARGO, D R. SÁNCHEZ, C. Lembranças e histórias de um vale encantado: A educação Ambiental popular através da metodologia investigação ação participante (IAP) na proteção de saberes locais no Vale do Jequitinhonha.VIII Encontro de Pesquisa em Educação Ambiental, Rio de Janeiro. Anais, Rio de Janeiro: EPEA, p. 1-15, 2015.

CAMARGO, D R. Lendas, rezas e garrafadas: Educação Ambiental de base comunitária e os saberes locais no Vale do Jequitinhonha. 2017. Dissertação (Mestrado), Programa de Pós- Graduação em Educação, UNIRIO. Rio de Janeiro, 2017. 
Ensino, Saúde e Ambiente - v. 14 n. esp. (2021): Dossiê Paulo Freire para além dos 100 anos: construir utopias, transformar a realidade, p. 512-535.

Questão Ambiental e Promoção da Saúde

DELIZOICOV, D; DELIZOICOV, N, C. Educação Ambiental na Escola. In: LOUREIRO, C F B.; TORRES, J R. (orgs.). Educação Ambiental: Dialogando com Paulo Freire. São Paulo: Cortez, 2014.

FREIRE, P. Ação cultural para a liberdade. Rio de Janeiro, Paz e Terra, 1981.

FREIRE, P. Pedagogia do Oprimido. Rio de Janeiro: Paz \& Terra. 1987.

FREIRE, P. Pedagogia da Autonomia. Saberes necessários à prática educativa. São Paulo: Paz e Terra, 1996.

FREIRE, P. À sombra desta mangueira. Organização e Notas de Ana Maria Araújo Freire. Rio de Janeiro: Paz e Terra, 2015.

FIGUEIREDO, J B. A. As Contribuições de Paulo Freire par uma Educação Ambiental Dialógica. Anais 29 Reunião Anped, Caxanbu, p. 1- 16, 2006.

JACOB, L. "Vandana Shiva", Mestras e Mestres do Mundo: Coragem e Sabedoria, 2019. Disponível em:

https://alice.ces.uc.pt/mestrxs/?id=27696\&pag=23918\&id lingua=1\&entry=31904. Acesso: 21/06/2021.

KOTHARI, R. Prólogo. In: SHIVA, V. Abrazar la vida. Mujer, ecologia e supervivência. Madri: Horas y Horas. 1995.

KIRJNER, D. A inserção do Ecofeminismo no contexto acadêmico brasileiro. In: RESENDO, D.; OLIVEIRA, F. A. G.; CARVALHO, P.; KUHNEN, T. A (Org.). Ecofeminismos.

Fundamentos teóricos e práxis interseccionais. Rio de Janeiro: Ape’Ku, 2019.

LAYRARGUES, P P. Educação Ambiental com compromisso social: O desafio da superação das desigualdades. In: LOUREIRO, C.F.B.; LAYRARGUES, P.P.; CASTRO, R. de S. (orgs.). Repensar a Educação Ambiental: um olhar crítico. São Paulo: Cortez. p. 11-31, 2009.

LAYRARGUES, P P.; LIMA, G, F. C. As macrotendências político-pedagógicas da educação ambiental brasileira. Ambiente \& Sociedade, São Paulo, v.17, n. 1 p. 23- 40, 2014.

LAYRARGUES, P P. Pandemias, colapso climática, antiecologismo: Educação Ambiental entre as emergências de um ecocídio apocalíptico. Revbea, São Paulo, v. 15, n. 4, p. 1-30, 2020 .

LEFF, E. Ecologia, capital e cultura: a territorialização da racionalidade ambiental. Petrópolis: Vozes, 2009.

LEFF, E. Complexidade, Racionalidade Ambiental e Diálogo de Saberes. Educação e realidade, Porto Alegre, v. 34, n. 3, p. 17-24, 2009.

LOUREIRO, C F B. Trajetória e Fundamentos da Educação Ambiental. São Paulo: Cortez, 2009.

LOUREIRO, C F B.; FRANCO, Jussara B. Aspectos teóricos e metodológicos do Círculo de Cultura: uma possibilidade pedagógica e dialógica em Educação Ambiental. In. LOUREIRO, 
Ensino, Saúde e Ambiente - v. 14 n. esp. (2021): Dossiê Paulo Freire para além dos 100 anos: construir utopias, transformar a realidade, p. 512-535.

Questão Ambiental e Promoção da Saúde

Carlos, Frederico, B.; TORRES, Juliana R. (orgs.). Educação ambiental dialogando com Paulo Freire. São Paulo: Cortez, 155- 180, 2014.

LOUREIRO, C F B.; LAYRARGUES, Philippe P. Ecologia Política, Justiça e Educação Ambiental Crítica: Perspectivas de aliança contra-hegemônica. Trabalho Educação e Saúde, Rio de Janeiro, v. 11 n. 1, p. 53-71, 2013.

LOUREIRO, C F B. Educação Ambiental. Questões de vida. São Paulo: Cortez, 2019.

MACHADO, R de C F. Fome. In: STRECK, Danilo R.; REDIN, Euclides; ZITKOSKI, Jaime J. (orgs.) Dicionário Paulo Freire. São Paulo: Autêntica, p. 202-203, 2015.

MARTÍNEZ ALIER, J.; VENTOSA, I. P.; OMEDES, A. M. O. (Ed.). Ecofeminismos y ecologías políticas feministas. Icaria: Catalunya, 2017.

MIES, M; SHIVA V. Ecofeminismo. Lisboa: Instituto Piaget, 1993.

OLIVEIRA, C A. G.; SÁNCHEZ, C P. Educação ambiental, justiça ambiental e questões de gênero: a perspectiva de um grupo de educadoras ambientais comunitárias de Magé, RJ.

Revista Eletrônica do Mestrado em Educação Ambiental, Rio Grande, v. 35, n. 1, p. 151170, 2018.

OLIVEIRA, C. A. G.; ROJAS, L. A. P.; PRADA, K. A. F.; SALGADO, S. D. C. O que os Movimentos de Mulheres e os Ecofeminismos do Sul nos ensinam? Apontamentos para a Educação Ambiental de Base Comunitária. In: ACCIOLY, I. ; PELACANI, B.; SÁNCHEZ, C. (orgs.) Dossiê: Educação Ambiental: Insurgências, Re- existências e esperanças. Ensino, saúde e ambiente, Niterói, Número Especial, p.180-204, 2020.

OXFAN. Menos de 1\% das propriedades agrícolas é dona de quase metade da área rural brasileira. 2019. Disponível em: https://www.oxfam.org.br/publicacao/menos-de-1das-propriedades-agricolas-e-dona-de-quase-metade-da-area-rural-brasileira/. Acesso: $15 / 06 / 2021$.

SARRIA, J A. V.; PELACANI, B; ESPINOSA, Gloria M. F.; CAMARGO, Daniel R.; SÁNCHEZ, Celso. La Educación Ambiental Comunitária: Reflexiones, problemáticas y retos. In: KASSIADOU, Anne; SÁNCHEZ, Celso; CAMARGO, Daniel R.; STORTTI, Marcelo A.; COSTA, Rafael N. (orgs.). Educação Ambiental desde EI Sur. Macaé: Editora NUPEM, p. 50- 74, 2018.

SHIVA, V. Os sem- abrigo“Aldeia Global”. In MIES, Maria; SHIVA Vandana.

Ecofeminismo. Lisboa: Instituto Piaget, p. 133- 143, 1993.

SHIVA, V. Reducionismo e regeneração: Uma crise na ciência. In MIES, Maria; SHIVA, Vandana. Ecofeminismo. Lisboa: Instituto Piaget, p. 37- 52, 1993.

SHIVA, V. Abrazar la vida. Mujer, ecologia e supervivência. Madri: Horas y Horas. 1995.

SHIVA, V. A monocultura da mente. Perspectivas da biodiversidade e da biotecnologia. São Paulo: Gaia, 2003. 
Ensino, Saúde e Ambiente - v. 14 n. esp. (2021): Dossiê Paulo Freire para além dos 100 anos: construir utopias, transformar a realidade, p. 512-535.

Questão Ambiental e Promoção da Saúde

SHIVA, V. Guerras por Água: privatização, poluição e lucro. São Paulo: Radical Livros, 2006.

SILIPRANDI, E. Mulheres agricultoras no Brasil: sujeitos na luta por soberania e segurança alimentar. Pensamento iberoamericano. p. 169-183, 2012.

SVAMPA, M. Feminismos del Sur y ecofeminismo. Nueva Sociedad, n. 256, p. 127-131, 2015. Disponível em: http://nuso.org/articulo/feminismos-del-sur-y-ecofeminismo/, $\quad 4.12 .16$. Acesso:13/04/2019.

\section{SOBRE A AUTORA}

\section{CAROLINA ALVES GOMES DE OLIVEIRA}

Doutora em Educação (UNIRIO), mestre em Biologia Marinha ( UFF), graduada em Ciências Biológicas. É pesquisadora do GEASur/ UNIRIO e educadora popular, atuando nas interfaces entre a educação ambiental e educação popular com foco nas resistências das mulheres. 